Archived version from NCDOCKS Institutional Repository http://libres.uncg.edu/ir/asu/

Alm, J., Deskins, J., \& McKee, M. (2009). Do individuals comply on income not reported by their employer? Public Finance Review, 37(2), 120-141. ISSN: 1552-7530. doi: 10.1177/1091142108322878

\title{
Do Individuals Comply on Income Not Reported by Their Employer?
}

\author{
James Alm, John Deskins, Michael McKee
}

\begin{abstract}
Individuals with income not reported to the tax authority by a third party (e.g., the selfemployed, those earning tips) may be less likely to be detected evading taxes relative to the case in which their income is subject to third-party reporting. However, their compliance responses-to changes in the proportion of income that is reported to the tax authority, to changes in audit and tax rates, etc.-are largely unknown, in part because of the difficulty in obtaining information on individual choices in these situations. The authors use experimental methods to examine individual income tax compliance in settings where individuals differ in the portion of their income that is "matched" (reported to the tax authority via third-party information) versus "nonmatched" (not fully reported to the tax authority). The results indicate that individuals who have relatively more non-matched income exhibit significantly lower tax compliance rates than individuals who earn relatively less non-matched income.
\end{abstract}

Keywords: tax compliance; informal sector; experimental economics 


\section{Introduction}

In the United States, as with many other countries, the manner by which personal income is reported to the tax authority can vary significantly by type of employment. For example, employers are required to report their employees' wage or salary income to the taxing authority, something that we refer to as a "matched income" arrangement. In contrast, the income of self-employed individuals and of those with casual earnings like tip income is typically not reported by the paying party, what we refer to as a "nonmatched income" arrangement. The lack of such third-party income reporting implies that tax evasion by those earning nonmatched income will be less likely to be detected via audits. As a result, individuals with nonmatched income are likely to exhibit lower tax compliance than those individuals with matched income.

There is a longstanding perception that third-party information affects compliance behavior. Much of the evidence has been derived from information on the selfemployed. Andreoni, Erard, and Feinstein (1998) cite 1988 statistics from the Taxpayer Compliance Measurement Program (TCMP) indicating that average tax understatements for individuals with farm and sole-proprietor income (or income not subject to reporting requirements) are $\$ 1,058$ and $\$ 827$, respectively, compared with an average overall understatement of $\$ 289$ across all individuals. As discussed in more detail later, empirical estimates of individual compliance decisions are also broadly consistent with the notion that evasion is determined in part by the source of income (e.g., wage income that is subject to matching versus income that is not subject to matching), with the amount of evasion generally higher for individuals who receive nonmatched income not subject to source withholding (Clotfelter 1983; Kagan 1989; Feinstein 1991; Alm, Bahl, and Murray 1993; Joulfaian and Rider 1998). Bruce (2000) also provides suggestive evidence that individuals enter into self-employment to exploit the greater tax evasion opportunities associated with self-employment. The behavior just described is, of course, consistent with rational response to the perceived lower likelihood that evasion will be detected (and punished) when the amount of information available to the tax authority is reduced. To date, however, the individual behavior of individuals in these matched- versus nonmatched-income settings remains largely unexamined.

The empirical evidence cited above is gleaned from analysis of field data. While we can obtain useful insights here, there are several aspects in which these data are inadequate for the analysis of compliance behavior. It is often impossible to disentangle evasion from responses to ambiguous instructions in the tax form, so that, for example, the numbers reported in Andreoni, Erard, and Feinstein (1998) may simply reflect the fact that the interpretations of legitimate deductions for self-employed persons are less precise than for those earning only matched wage or salary income. It is similarly impossible to know the taxpayers' individual estimates of audit probabilities and penalties. Since the field data often cover a single or a few years, there are often few changes in policy variables, something that makes it difficult to identify and so estimate individual responses to changes in enforcement efforts. Finally, we can observe compliance only for those taxpayers actually audited. Given that audits are imperfect, 
even when available (as from the TCMP) this information is subject to measurement errors.

For these reasons, field research on tax compliance has been complemented with data conducted via laboratory experiments. We follow this tradition here and report on behavior observed in a laboratory experiment designed to test whether individuals exhibit different tax compliance patterns when they receive different proportions of income that is perfectly detectable on audit (e.g., matched income) versus income that cannot be detected with certainty (e.g., nonmatched income).

Our experiments mimic a situation arising in the naturally occurring environment for individuals who receive two types of income: income that is reported to the tax authority by a third party (e.g., their employer), such as wages and salaries, and also income from unreported sources such as tips or from self-employment activities in which the income is not reported by the employer to the tax authority. 5 Our experimental design allows us to examine the behavior of individuals with different proportions of income subject to third-party information as they respond to different tax and audit rates, gross and relative income, and other factors in their tax compliance decisions. This information is especially relevant to policy questions that surround how government should design income tax reporting and auditing systems.

Our results indicate that individuals who receive relatively more nonmatched income exhibit significantly lower tax compliance rates than individuals who receive less nonmatched income. Our results also indicate that higher income levels, higher tax rates, and lower audit rates lead to increased tax evasion, but with responses that vary depending on the proportion of matched versus nonmatched income.

Of course, while experimental methods provide several advantages in examining patterns of evasion, we must be aware of their well-known shortcomings. For example, data are drawn from somewhat artificial laboratory environments that use student subjects, and experiments have difficulty capturing the catastrophic losses that may occur with detection and punishment. Even so, there is much emerging evidence that properly designed experimental methods have much external validity, and so we believe that our approach is a useful alternative to other, more traditional methods of analysis. We address the issue of external validity when we discuss our experimental design.

\section{Previous Literature}

Several empirical studies have used naturally occurring data, typically from the U.S. Internal Revenue Service (IRS), to examine differential patterns of compliance across matched versus nonmatched income sources. The difficulty of detecting income that is not subject to third-party reporting is described by Joulfaian and Rider $(1998,675)$ :

In large part, this disparity in reporting compliance is attributed to the lower probability of detecting unreported self-employment income; or conversely stated, the higher cost of detecting unreported self-employment income because of the absence of third-party reporting of income and income tax withholding. In contrast, we observe nearly 
complete reporting of wage income that is subject to third-party reporting and withholding.

Indeed, the differing compliance behavior between self-employed individuals and individuals in wage and salary employment has been the subject of considerable study. In a recent review of the literature on taxation and self-employment, Scheutze and Bruce (2004) conclude that noncompliance among the self-employed is a significant concern, citing research that finds that the self-employed sector of the economy makes a very significant contribution to the total level of tax evasion in the nation. One of the studies in their review (U.S. General Accounting Office 1990) estimates that for 1987 self-employed individuals account for 63 percent of the $\$ 48$ billion in unreported income. Relatedly, Kagan (1989) reports findings from an IRS study of tax returns that estimates that only 50.3 percent of nonfarm proprietor income in 1979 was voluntarily reported to the IRS compared to 93.9 percent of wage and salary income. Kagan (1989) also discusses another IRS study that examined individuals who were treated as independent contractors (and who had no income reported or withheld by a third party); this study found a low percentage of income reported overall, with 47 percent of the independent contractors not even reporting any of their earnings. Feinstein (1991) analyzes data from the IRS Taxpayer Compliance Measurement Program, and concludes that Schedule C (own business) and Schedule F (farm) filers are much more likely to evade than the average taxpayer. Evidence from developing countries also supports this notion.

For example, Alm, Bahl, and Murray (1993) use audited individual tax returns from Jamaica, and find that evasion is significantly larger for individuals who have income sources not subject to matching requirements.

The empirical literature has also found suggestive evidence that individuals enter into self-employment to take advantage of noncompliance opportunities. Recently, Bruce (2000) finds that higher tax rates, as well as the differential between the marginal tax rates on wage and salary and selfemployment, both increase self-employment. He asserts that a likely explanation for this result is that individuals may enter into selfemployment to exploit the opportunities to evade taxes; that is, higher effective tax rates on matched income may drive individuals into self-employment to take advantage of the associated evasion opportunities on nonmatched income. Anecdotal evidence from developing countries also supports this notion.

A recent study by Gerxhani and Schram (2006) uses experimental methods to better understand the choice of income source and its impact on subsequent tax evasion. In their design, subjects in Albania and the Netherlands are allowed to choose between earning "registered" and "unregistered" income; the amount of registered income is known with certainty to the experimenter, while the amount of unregistered income is known to the experimenter only with some probability. After income is determined, subjects must choose how much income to report and so how much taxes to pay. Registered income is audited with certainty, which implies that any income not reported will be discovered and fines imposed; unregistered income is audited with some known 
probability, so that subjects with unregistered income may be able to evade taxes on unreported income if they are not audited. Their results provide evidence that, when tax evasion is possible via the choice of unregistered income, subjects are more likely to choose unregistered income.

The results of Gerxhani and Schram (2006) are important and relevant to our work, since their "unregistered income" resembles what we define here as "nonmatched income." Their focus, however, is on whether individuals are more likely to choose an income source (or an "occupation") with greater amounts of "unregistered income"indeed, individuals are more likely to make this choice-and whether subsequent evasion behavior differs across taxpayers who choose unregistered income versus those who choose registered income occupations-indeed, again, behavior differs. Put differently, Gerxhani and Schram (2006) are mainly interested in examining the performance of the "informal sector" (or the sector in which individuals are not as likely to be caught if they do not report fully their income): are individuals more likely to choose to work in the informal sector because they may then be better able to cheat on their taxes? By their choice of countries in which to conduct the experiments, Gerxhani and Schram (2006) also investigate the effect of trust in the fiscal institutions on the individual choice of whether to work in the formal or the informal sector.

Our interest here is in the design of actual institutions of tax collection. Specifically, we investigate two questions: how is individual tax reporting affected when the use of thirdparty sources of information varies across income types, and how do individuals with different proportions of income subject to third-party information respond to changes in tax rates, audit rates, gross income, and other factors in their tax compliance decisions? We are mainly interested in examining the performance of the tax authority, especially in the design of fiscal institutions that are more effective in collecting taxes. While the Gerxhani and Schram (2006) study yields useful insights, clear conclusions regarding the determinants and magnitude of tax evasion among taxpayers subject to different reporting requirements remain elusive. Our experiments are the first to provide insights on these issues.

Why do we use experimental methods? As noted earlier, the primary difficulty here is the lack of fully reliable naturally occurring data, given that evasion is so difficult to capture. In addition, there are other confounding effects with naturally occurring data that make clear estimates of tax noncompliance difficult to obtain, such as the existence of ambiguous tax laws and the presence of nonfilers.13 Even if naturally occurring data on the individuals with different amounts of income subject to third-party information are available, such data are subject to the obvious problem that there are numerous factors that may affect behavior, factors that are difficult (if not impossible) to identify and to control for; put differently, naturally occurring data are unable to differentiate between the various causes that may encourage (or discourage) evasion, and such data are especially unable to control for these different causes. Experimental data offer significant advantages: compliance rates from experiments are accurate, and each variable that affects compliance can be identified and controlled for in the experimental design. In particular, our experimental design specifically allows us to isolate the lower 
detectability that may accompany, say, self-employment income versus wage income, to determine the impact on the compliance behavior of subjects. Our design also allows us to vary the relevant fiscal parameters, to determine the impact of changes in, say, audit rates on compliance decisions. The next section discusses our experimental design.

\section{Experimental Design}

Our experimental structure replicates the fundamental elements of the voluntary reporting system of the U.S. individual income tax. Subjects earn income by performing a simple task and are told what percentage of their total income is "matched income" and what percentage is "nonmatched income." They then complete a tax return where they may report none, some, or all of each type of income to the taxing authority, and pay taxes at an announced rate on all income that is reported. Income not reported is not subject to the income tax. However, individuals may be audited, where the audit is randomly determined with a known and announced probability. If a subject is audited, all matched income that is not reported is discovered and nonmatched income that is not reported is discovered but only with some probability. Audit and detection rates are announced. If the individual is not in compliance and if this noncompliance is detected, then he or she pays the additional taxes owed plus a penalty that is a multiple of the unpaid taxes.

This setting provides for the necessary degree of "parallelism" to the naturally occurring world that is crucial to the application of experimental results to policy (Smith 1982; Plott 1987). The experimental setting need not attempt to capture all of the variation in the naturally occurring environment, but it should sufficiently re-create the fundamental elements of the naturally occurring world if the results are to be relevant in policy debates. In this regard, our experimental design uses tax language, which is presented via the subject interface, and requires that the subjects earn income in each period and disclose this income in the same manner as in the typical tax form. As in the naturally occurring setting, there is a time limit on the filing of income, and the clock at the bottom of the screen reminds the subjects of this. There is a penalty for failing to file on time. The incomes vary across the subjects each period, and only the subjects know their own income.

The experiment proceeds in the following fashion. Each subject sits at a computer located in a cubicle, and is not allowed to communicate with other subjects. The instructions are conveyed by a series of computer screens that the subjects read at their own pace. Clarification questions are addressed after the subjects have completed the instructions and two practice rounds. The subjects are informed that all decisions will be private; the experimenter is unable to observe the decisions and does not move about the room once the session starts. This reduces, as much as possible, both peer and experimenter effects that could affect the decisions of the subjects. All actions that subjects take are made on the computer. In each round of the experiment, subjects earn income based on their performance in a simple computerized task, in which they are required to move numbers in the correct order from one location on the computer screen to another location. The subject who finishes the task with the quickest time 
earns the highest income (100 "lab dollars"); the second and third place finishers earn 90 lab dollars each, the fourth and fifth place finishers earn 80 lab dollars each, and so on, with ties broken randomly. Subjects are informed of their earnings and those of the others in their group to ensure that they believe the relative nature of the earnings. These earnings represent the only information subjects have of other participants.

After earning income, subjects are presented with a screen that reports their income as well as the tax-policy parameters. These parameters include the audit rate, the penalty rate, and the tax rate. Importantly, subjects are told the percentage of their total income that can be matched by the tax authority (and the corresponding percentage that is nonmatched). They are also told that any matched income that is unreported will be discovered with certainty in the event of an audit, while any nonmatched income that is unreported will be discovered in an audit, but only with some known and announced probability reflecting the productivity of the audit of nonmatched income. Subjects then choose how much of their matched and nonmatched income to report to the tax authority. They are able to report any amount between zero and their total earnings (no decimals) of each type of income. Tax liability is computed for the subjects based on the fractions of matched and nonmatched income reported. Subjects can experiment with different income reports during the time allowed for filing. For each potential report, the computer computes their final income in the event the subject is audited and in the event the subject is not audited. Subjects may also view their history of previous rounds during this period. The timer located at the bottom of the screen counts down the remaining time and begins to flash when there is fifteen seconds remaining.

Audits are determined by the use of a "virtual" bingo cage that appears on each subject's computer screen. A box with ten balls (blue and white) appears on the screen following the tax filing. The balls begin to bounce around in the box and after a brief interval a door opens at the top of the box. If a blue ball exits, the subject is audited; a white ball signifies no audit. The fraction of blue balls determines the audit probability. The audit applies only to the current period declarations, not to previous (or future) periods. The computer automatically deducts taxes paid and penalties (if any are owed) from subjects' accounts. Any taxes and penalties paid are not distributed to the subjects. As noted above, the tax revenues are not used to provide a public good in this set of experiments to ensure that the subjects focus on the individual income disclosure decision.

After-tax income for each round is represented by the equation:

$$
\begin{aligned}
\text { After-tax Income }= & G-t G\left[M^{*} r_{m}+u^{*} r_{u}\right] \\
& -A t(1+F) G\left[M\left(1-r_{m}\right)+D u\left(1-r_{u}\right)\right],
\end{aligned}
$$

Where 
$G=$ gross (eamed) income,

$T=\operatorname{tax}$ rate,

$M=$ proportion of gross income that is matched,

$r_{m}=$ proportion of matched income reported by the subject,

$u=$ proportion of gross income that is nonmatched $=(1-M)$,

$r_{u}=$ proportion of nonmatched income reported by the subject,

$A=1$ if individual is audited and 0 otherwise,

$F=$ penalty rate on unreported taxes, and

$D=$ if subject is detected on not fully reporting nonmatched income and 0 otherwise.

Subjects are informed that they keep their after-tax earnings at the end of the experiment, converted from lab dollars to U.S. dollars at the rate of 100 lab dollars to 1 U.S. dollar, and paid in cash and in private. After income is reported and an audit (if any) is determined, subjects see one final screen that summarizes everything that happened during the round. This process is repeated for a fixed (but unannounced) number of rounds.

The experimental design (see table 1) applies five combinations of matched versus nonmatched income: 0 percent, 25 percent, 50 percent, 75 percent, and 100 percent nonmatched (and the corresponding matched percentages). There are three different tax rates: 20 percent, 35 percent, and 50 percent. We use a between-subject design for both of these variables; that is, these parameters are varied only between sessions, and any particular subject sees only one combination of matched and nonmatched income and only one tax rate.

The probability of audit is a treatment variable and is assigned a value of 10 percent or 30 percent. These rates are much higher than actual full audit rates in the United States. However, the IRS conducts a range of

Table 1 Experimental Design

\begin{tabular}{lcccc} 
Treatment & $\begin{array}{c}\text { Percent } \\
\text { Nonmatched }\end{array}$ & $\begin{array}{c}\text { Tax } \\
\text { Rate }\end{array}$ & $\begin{array}{c}\text { Audit } \\
\text { Probability }\end{array}$ & $\begin{array}{c}\text { Probability } \\
\text { of Detection }\end{array}$ \\
\hline 1 & 0 & 35 & 10 and 30 & - \\
2 & 25 & 35 & 10 and 30 & 50 \\
3 & 50 & 35 & 10 and 30 & 50 \\
4 & 75 & 35 & 10 and 30 & 50 \\
5 & 50 & 35 & 10 and 30 & 75 \\
6 & 50 & 35 & 10 and 30 & 25 \\
7 & 50 & 20 & 10 and 30 & 50 \\
8 & 50 & 50 & 10 and 30 & 50 \\
9 & 100 & 35 & 10 and 30 & 50
\end{tabular}

audits and for many types of audits the rates are quite high. In our design, the probability that an individual is detected evading taxes varies between matched and nonmatched income. The probability of detection is 100 percent for matched income; if 
an individual is audited, any matched income that is unreported is discovered with certainty. However, for nonmatched income the detection rates vary among 25 percent, 50 percent, and 75 percent. The penalty rate on unreported income is set at a rate of 50 percent; on detected noncompliance, an individual must pay discovered undeclared taxes plus a penalty of 50 percent of undeclared taxes.

Each session involves two stages, each with fifteen rounds, with the audit rate the only parameter that changes between the two stages. Earnings per subject were between $\$ 19$ and \$37 range, based on performance in the income-earning component, tax reporting, and chance (i.e., the audit process). The experimental design requires the administration of nine sessions, as outlined in table 1 . Sessions consist of 16,14, or 12 subjects, depending on show-up rates. In all, 124 subjects participated in the experiment.

The experimental platform consists of sixteen notebook computers, a server machine, and software designed for this series of experimentation. Sessions were conducted on the University of Tennessee campus using students recruited via announcements on campus. Potential subjects signed up via a Web page and are invited to participate in a specific session by e-mail. Subjects were not permitted to participate in more than one session, only subjects recruited specifically for a session were allowed to participate, and no subject had prior experience in this experimental setting. Methods adhere to all guidelines concerning the ethical treatment of human subjects.

\section{Behavioral Hypotheses and Analytical Approach}

The experimental setting described above allows for an examination of several behavioral hypotheses. The first hypothesis is our main focus:

H1: Individuals are more likely to evade taxes when a larger share of their income is of the type that is not perfectly detectable by the tax authority; that is, the compliance rate falls as the percentage of income received as nonmatched income increases.

The ability of the tax authority to detect the true level of income clearly affects the expected value of compliance versus evasion and, accordingly, affects compliance in a rational tax-evasion model. However, this issue remains an empirical question, for several reasons. First, as has been demonstrated in numerous settings, individuals may not act in accordance with a rational tax-evasion model. Second, and more importantly, we are able to examine the impact in our controlled experimental environment of changes in the exact probability at which certain income types are detected. This is a crucial advantage of experimental methods over data (even if available) from the naturally occurring world. If we are able to show that less than perfectly detectable income increases tax evasion, an examination of individual responses to the probability of detection provides information that can be used in evaluating policies that affect the likelihood that certain income types could be detected on audit. 
The remaining hypotheses have been examined before in the literature. We conduct a reexamination here mainly for the purposes of complementing the matched/nonmatched income component of the study and also because our overall experimental design can be validated if our results here match those of earlier studies.

A second hypothesis is that evasion increases with higher tax rates:

H2: Higher tax rates have an uncertain impact on compliance.

It is well established that, in theory, a higher tax rate has conflicting effects on compliance (Allingham and Sandmo 1972). A higher tax rate increases the incentive for cheating, thereby increasing the amount of evasion. However, a higher tax rate also lowers income, and with decreasing absolute risk aversion, lower income makes an individual more risk averse reducing tax evasion. However, as Yitzhaki (1974) demonstrates, when the penalty is imposed on evaded taxes (not evaded income), the substitution effect disappears, and tax compliance is predicted to increase as the tax rate increases. However, most empirical and experimental work finds that there is a negative relation between tax rates and tax compliance.

Similarly, audit rates change the expected value of reporting income versus not reporting, and should affect tax compliance. It is straightforward to demonstrate via comparative statics exercises of the evasion gamble that compliance increases with higher audit rates:

H3: Higher audit rates lead to higher levels of tax compliance.

Wealth may also affect tax compliance by affecting the marginal utility of another dollar of income and, correspondingly, one's risk preferences, although this effect depends on one's attitudes toward risk:

H4: Compliance will be decreasing in income.

The evasion decision is based on the expected utility of reporting income versus not reporting. Table 2 reports the difference in the expected value of reporting 100 dollars of income versus not reporting any income for matched and nonmatched income, for each tax rate, audit rate, and nonmatched income detection probability combination used in experimental design. If individuals were motivated only by selfish preferences and were risk neutral, these expected value calculations would predict behavior without error, and individuals would exhibit all-or-none behavior, choosing to report, say, all matched income or none it (or, say, all nonmatched income or none of it).21 Risk aversion will induce greater compliance, as will factors such as social norms and "other-regardingpreferences." If individuals exhibit decreasing absolute risk aversion, then compliance will fall as income increases. The effect of norms and other-regarding-preferences may counter that if these are normal goods. 
The expected value calculation is important because it provides the benchmark of a risk neutral agent with purely selfish preferences. We have structured the parameters such that, for a risk neutral individual, it is rational to evade in most cases, to increase the parallelism of our design with that of the naturally occurring world where evasion is typically the rational choice. Thus, the difference between the expected value of compliance and the expected value of noncompliance is negative in all but one

Table 2 Should a Risk Neutral Individual Comply?

\begin{tabular}{|c|c|c|c|}
\hline \multicolumn{4}{|c|}{ Matched Income } \\
\hline $\begin{array}{l}\text { Tax } \\
\text { Rate }\end{array}$ & & $\begin{array}{c}\text { Audit } \\
\text { Rate }\end{array}$ & $\begin{array}{l}\text { Expected Value of Compliance- } \\
\text { Expected Value of Noncompliance }\end{array}$ \\
\hline 35 & & 10 & -26.5 \\
\hline 20 & & 10 & -13.0 \\
\hline 50 & & 10 & -40.0 \\
\hline 35 & & 30 & -9.5 \\
\hline 20 & & 30 & 1.0 \\
\hline 50 & & 30 & -20.0 \\
\hline \multicolumn{4}{|c|}{ Nonmatched Income } \\
\hline $\begin{array}{l}\text { Tax } \\
\text { Rate }\end{array}$ & $\begin{array}{l}\text { Probability } \\
\text { of Detection }\end{array}$ & $\begin{array}{l}\text { Audit } \\
\text { Rate }\end{array}$ & $\begin{array}{l}\text { Expected Value of Compliance-Expected } \\
\text { Value of Noncompliance }\end{array}$ \\
\hline 35 & 50 & 10 & -28.2 \\
\hline 35 & 75 & 10 & -29.8 \\
\hline 35 & 25 & 10 & -26.6 \\
\hline 20 & 50 & 10 & -14.0 \\
\hline 50 & 50 & 10 & -42.5 \\
\hline 35 & 50 & 30 & -14.7 \\
\hline 35 & 75 & 30 & -19.5 \\
\hline 35 & 25 & 30 & -9.8 \\
\hline 20 & 50 & 30 & -1.9 \\
\hline 50 & 50 & 30 & -27.4 \\
\hline
\end{tabular}

case (e.g., where there is a low tax rate and a high audit rate on matched income). Evading nonmatched income always carries a larger expected gain relative to matched income, all else equal. We begin with an analysis of simple descriptive statistics but our primary hypothesis testing utilizes a panel estimation model (generalized least squares or GLS). We include subject-specific effects to control for individual-specific characteristics, and we allow for heteroscedasticity across individuals (panels). Income tax compliance is measured as the percentage of gross income reported to the tax authority and is assumed to depend on gross income, the percent nonmatched, the tax rate, the audit success rate (or the probability that unreported nonmatched income is discovered in the event of an audit), and the probability of detection, or

$$
\begin{aligned}
\text { Percent of Gross Income Reported } & =\beta_{i, t}+\beta_{1} \text { Gross Income }_{i, t} \\
& +\beta_{2} \text { Percent Nonmatched }_{i, t} \\
& +\beta_{3} \text { Tax Rate }_{i, t}+\beta_{4} \text { Audit Success Rate }_{i, t} \\
& +\beta_{5} \text { Audit Probability }_{i, t}+\varepsilon_{i t},
\end{aligned}
$$


where $\mathrm{i}$ and $\mathrm{t}$ are individual and round indices and eit $1 / 4$ uipwit. The traditional error term is denoted wit , and is assumed to meet all of the usual requirements. The individualspecific effect is denoted ui; and controls for individual-level heterogeneity. We have estimated a wide variety of alternative specifications, and our results are robust to these alternative specifications.

\section{Results}

The simplest analysis of our experimental results examines descriptive statistics on the effects of the various fiscal variables (e.g., matched versus nonmatched income, tax rates, audit rates, probability of detection, gross income) on the level of individual compliance rates, where the compliance rate is calculated by dividing reported income by gross (or total) income.

The aggregate compliance rate for matched income is 54.2 percent, for nonmatched income it is 41.4 percent, and for total income it is 47.6 percent. These aggregate results indicate that individuals report a much lower percentage of their nonmatched income relative to matched income, providing support of the primary hypothesis $(\mathrm{H} 1)$. The difference for matched versus nonmatched income is statistically significant $(0.05$ level). A graphical presentation illustrates this point as well. Figure 1 presents the distribution of average tax compliance rates for individuals, over thirty rounds, for matched and nonmatched income. The histogram presents groupings over aggregate compliance rates. As with much of the earlier literature (e.g., Alm, Jackson, and McKee 1992) observations are concentrated at the extremes. Figure 1 also indicates that a noticeably larger portion of the nonmatched sample falls into the 0 to 20 average compliance rate range, while a larger percentage of the matched sample falls into the 81 to 100 range. Indeed, 49.9 percent of the subjects exhibit compliance rates that fall into the 81 to 100 percent range on their matched income, while only 32.8 percent of individuals exhibited compliance rates this high for their nonmatched income.

Figure 1 Distribution of Average Compliance Rates

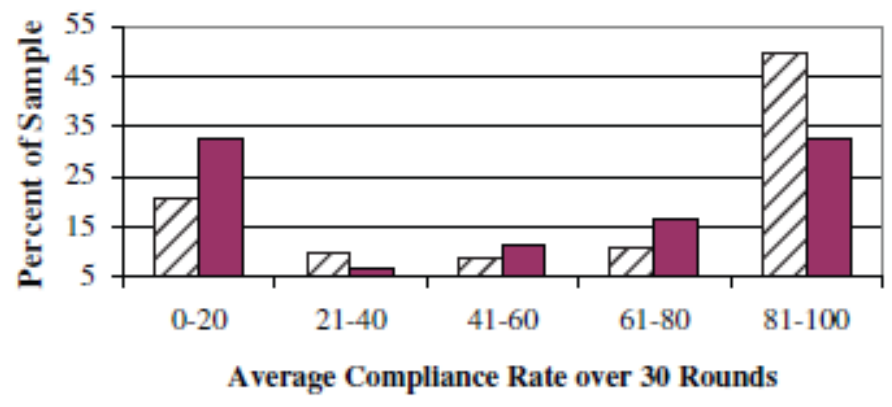

$\square$ Matched $\square$ Nonmatched 
Figure 2 Compliance Rates by Nonmatched Share

Figure 2

Compliance Rates by Nonmatched Share

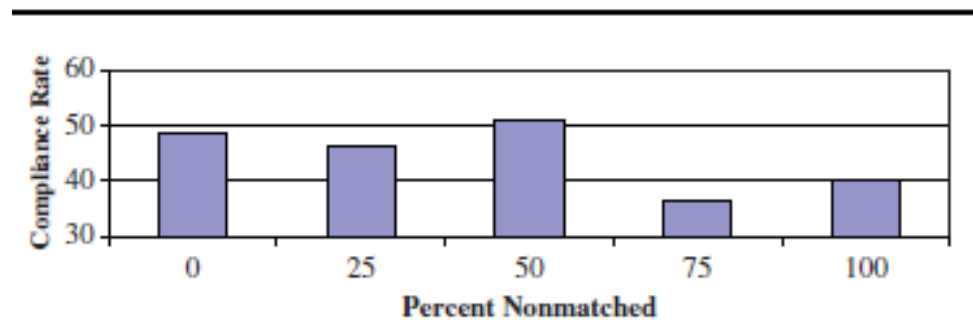

Figure 2 presents overall compliance rates by the percentage of income that is nonmatched, or $\mathrm{H} 1$ (e.g., compliance decreases as more of an individual's income is nonmatched). These aggregate data do not support our conjecture that compliance will fall as the share of nonmatched income increases. There is a slight downward trend overall, but compliance is actually highest when subjects receive half of their income from nonmatched sources. Of course, these simple presentations do not control for other factors that may influence tax compliance behavior.

Our data set constitutes a panel of 124 subjects making thirty individual decisions. We elected to utilize a feasible generalized least squares panel estimation procedure correcting for panel (individual) specific heteroskedastic errors (Wooldridge 2002). Results from different specifications are presented in table 3. Because our interest is in the overall level of compliance, we do not estimate the compliance levels for matched and

Table 3 Estimation Results

\begin{tabular}{lccc} 
Independent Variables & Model 1 & Model 2 & Model 3 \\
\hline Constant & $119.88^{* * *}$ & $139.43^{* * *}$ & $119.48^{* * *}$ \\
Percent nonmatched & $(7.35)$ & $(7.31)$ & $(7.49)$ \\
& $-0.062^{* *}$ & $-0.054^{* *}$ & $-0.053^{*}$ \\
Audit success rate & $(0.027)$ & $(0.026)$ & $(0.027)$ \\
& $0.150^{* * *}$ & $0.104^{*}$ & $0.163^{* * *}$ \\
Audit probability & $(0.057)$ & $(0.056)$ & $(0.058)$ \\
& $0.245^{* * *}$ & $0.245^{* * *}$ & $0.289^{* * *}$ \\
Tax rate & $(0.070)$ & $(0.068)$ & $(0.074)$ \\
& $-0.776^{* * *}$ & $-1.023^{* * *}$ & $-0.782^{* * *}$ \\
Gross income & $(0.098)$ & $(0.098)$ & $(0.100)$ \\
Prepare own taxes & $-0.660^{* * *}$ & $-0.693^{* * *}$ & $(0.067)$ \\
& $(0.065)$ & $(0.064)$ & - \\
Audit last round & - & $-20.744^{* * *}$ & -1.645 \\
Wald $\chi^{2}$ & - & $(1.524)$ & $(1.865)$ \\
Log-likelihood & -19244 & - & -18549 \\
Panels/observations & $124 / 3720$ & -19154 & $124 / 3580$
\end{tabular}


nonmatched income separately. The dependent variable is again the percent of total income reported to the tax authority.

Results from the baseline model (model 1) are presented in the first column of table 3. These estimation results support the primary hypothesis $(\mathrm{H} 1)$ : tax compliance decreases as individuals earn larger shares of nonmatched income ("Percent Nonmatched"). Our estimates indicate that the tax compliance rate declines by 1.6 percentage points as the percent nonmatched increases by 25 percentage points. Relative to an average tax compliance rate of 47.6 percent, this indicates a fairly small elasticity.

Also as expected, our estimation results indicate that a higher "Audit Success Rate" (or the probability that unreported nonmatched income is discovered in the event of an audit) leads to higher rates of tax compliance; however, the effect is not large. The compliance rate increases by 3.8 percentage points for an increase in the audit success rate of 25 percentage points.

The "Tax Rate" is statistically significant $(\mathrm{H} 2)$. A tax rate increase from 35 percent to 50 percent lowers compliance by 11.6 percentage points, a large change when considering average compliance rates. A higher "Audit Probability" also leads to significantly higher rates of compliance $(\mathrm{H} 3)$. Increasing the audit probability from 10 to 30 percent increases compliance by 4.9 percentage points, all else equal. These tax rate and audit rate results are consistent with some earlier findings (see Alm, Jackson, and McKee 1992). Our results also indicate that higher "Gross Income" is associated with significantly lower levels of tax compliance. An increase from 90 to 100 lab dollars lowers the percentage of income reported by 6.6 percentage points.

Given the context heavy experimental setting, we expect that subjects may bring their experience with the tax system to the lab. In model 2 (table 3), we include a dummy variable denoting whether the individual denoting whether an individual prepares his or her own tax return ("Prepare Own Taxes"). Individuals checking "no" on this follow-up question are likely to be included as dependents on their parents' tax returns. Thus, this variable may also capture whether the individual is independent, has additional work experience, and, perhaps most importantly for our purposes, has thought about the audit possibilities in the naturally occurring setting in which tax decisions are made. Interestingly, the coefficient on this variable is significant and negative, so that individuals with greater experience with the tax system are less likely to comply in our setting. Other demographic variables (e.g., age, gender) collected at the completion of the experiment were not significant. Our results indicate that income reporting rates are 20.7 percentage points lower for individuals who file their own tax return than for those who do not. The remaining coefficients are largely unchanged from model 1 . In particular, the coefficient on the percent of income that is not matched is still negative and significant.

Model 3 includes a variable to denote whether an individual was audited in the previous round ("Audit Last Round"). Since our audit process is purely random, a rational subject 
will treat each round as independent, so that the predicted coefficient on lagged audit is zero. As the results in table 3 show, this is the case here. The coefficient on nonmatched income is not different from that in model 2.

Our results demonstrate that tax compliance decreases with higher tax rates, consistent with other empirical and experimental work (Clotfelter 1983; Alm, Bahl, and Murray 1995; Alm, Jackson, and McKee 1992). As expected, compliance rates increase as the audit rates increases. Finally, our results suggest that higher levels of nonmatched income are associated with lower levels of tax compliance. This effect is robust across specifications.

\section{Conclusion}

Our results indicate that individuals who earn a larger share of income that is difficult to detect exhibit significantly lower rates of tax compliance. Even so, the question is still not completely resolved as to why the self-employed (whose income is presumably more difficult to detect) exhibit differing rates of compliance, and also different responses in their compliance decisions, than those who are in wage and salary employment. Our research provides some evidence that one possible explanation for higher rates of noncompliance among this group is lower rates of detection associated with their income. Institutional factors, such as the lack of income withholding for the self-employed or the greater degree of complexity of tax returns than those of individuals who earn wage and salary income may have an effect on compliance as well. More research is required to verify the effects of these other factors.

Some policy conclusions follow from our results. A tax authority adopting an endogenous selection audit rule will likely wish to increase its audit effort on taxpayers who earn income that cannot be matched with reports from the payer. Since U.S. filers provide an occupation class, the IRS could select returns for audit among occupations that generally have higher proportions of nonmatched income, such as those typically receiving substantial income from tips. It may also be desirable to subject matched income to higher withholding rates for those occupation classes, in effect imputing a higher marginal tax rate.

\section{Notes}

1. Such income is also subject to income tax withholding requirements and to the collection of payroll taxes.

2. There is some evidence that individuals adopt a portfolio approach to tax evasion, choosing to evade more in categories where expected penalties are lower (Martinez-Vazquez and Rider 2005; Cummings, Martinez-Vazquez, and McKee 2006).

3. With the current annual "tax gap" (e.g., the shortfall in personal income tax collection) estimated at over $\$ 300$ billion, it is likely that a substantial portion of this lies in the unreported income earnings. 4. As discussed in more detail later, an important recent exception is the work of Gerxhani and Schram (2006).

5. We note that tip income is far from incidental to those working in some sectors. The minimum wage for those in the food service sector was set at \$2.15 at the time of the study. Depending on the potential for tip earnings, employers may pay more than this. However, for many workers in this sector, tip income may be a substantial portion of earnings.

6. See Schram (2005) for a discussion of internal and external validity in economics experiments. 
7. There are of course other reasons for noncompliance in the self-employed sector. For example, there may be a lack of income tax withholding or a misunderstanding of the tax system that stems from less access to paid professional tax planners.

8. See also Witte and Woodbury (1985). They used IRS tax return data from the early 1970 s and found that tax compliance rates are higher in areas where relative more individuals are employed in the manufacturing sector (where individuals presumably earn relatively more wage and salary income). They interpret this finding as evidence that relatively more income that is reported by a third party, and is therefore more easily detectable, leads to relatively higher compliance rates.

9. See also Madeo, Schepanski, and Uecker (1987). The authors recruited a pool of seventy-one certified public accountants (CPAs) and presented them with a series of cases involving hypothetical taxpayers. Each case involved four factors, one of which was the source of income for the hypothetical taxpayer. The subjects then chose how much income that would be reported by the "typical" taxpayer. The authors found that their subjects predicted that those (hypothetical) individuals who earned significantly more selfemployment income would likely evade more.

10. See Robson and Wren (1999), who distinguish between the effects of marginal and average tax rates on self-employment, arguing that the latter are more related to evasion.

11. Our experimental design differs in many significant respects from that of Gerxhani and Schram (2006). Among other things, we impose the proportion of income that is matched versus nonmatched rather than allowing subjects to choose this proportion. We isolate the compliance decision from the choice of employment. Our setting reflects a common, naturally occurring setting such as service personnel in restaurants and bars. In our design, we vary the audit rates on nonmatched income; we require subjects to earn income by their performance in a simple task (rather than impose a fixed schedule of random incomes from which subjects are allowed to choose); we use a different set and range of fiscal parameters (e.g., tax, audit, and penalty rates); we use different group sizes; we use a different subject pool; we use a larger number of rounds (e.g., thirty versus eight). We do not include a public good financed from subject tax payments although we are cognizant of the fiscal exchange argument but suspect that it is manifest through the political market rather than a perceived link between own tax compliance and the quantity of the public good supplied. Alm, Jackson, and McKee (1993) demonstrate such a public choice link in a set of lab experiments.

12. For example, Clotfelter $(1983,367)$ states, in reference to data from the TCMP, that " ... income from moonlighting and cash-only businesses is very difficult even for trained auditors to identify."

13. See Erard and Ho (2001) for an empirical analysis of nonfilers.

14. Our basic experimental design and platform is similar to that of Alm and McKee (2006). The major difference here, of course, is the incorporation of matched versus nonmatched income.

15. Full instructions and screen images are available from the authors.

16. During the instructions, subjects are given the definitions of matched and nonmatched, and are told that a real-world example of nonmatched income is tip income. As noted above, tip income can constitute a significant share of total income for typical workers in the food and beverage service sector. During debriefing, our subjects indicated that they knew that tips could make up a considerable portion of earnings in the field.

17. This calculator simply computes the net income the subject would receive in the two alternate states of the world: audited and not audited. We include this feature so that we can focus on the behavioral decision-making aspect of the setting rather than be concerned with differences in subjects' ability to compute state-contingent outcomes.

18. While overall audit rates are quite low, among certain income and occupation classes they are more frequent. The oft-reported IRS audit rate (currently between 1 and 2 percent) is somewhat of an understatement. This reported rate usually refers to full audits only; in fact, the IRS conducts a wide range of audits including line matching and requests for information, and these are much more frequent. For example, in 2005 only 1.2 million individual returns (or less than one percent of the 131 million individual returns filed) were actually audited. However, in that year the IRS sent 3.1 million "math error notices" and received nearly 1.5 billion "information returns" from third parties, which are used to verify items reported on individual income tax returns.

19. Subjects are divided into two equal sized groups. This provides anonymity since the subjects do not know the identities of those in their group.

20. For example, consider the impact on after-tax income of a change in the proportion of matched income rm that is reported by the individual. This impact is positive if $A(1 \mathrm{pf})>1$, and is negative 
otherwise. Similarly, the impact on after-tax income of a change in the proportion of nonmatched income ru that is reported by the individual is positive if $A D 1 t p f)>1$, and is negative otherwise. These conditions indicate that the reporting decision is an all-or-none decision: either individuals report all matched (or nonmatched) income or they report none, depending on the values of the fiscal parameters.

21. Controlling for subject-specific effects is especially important because this allows us to isolate external factors that could blur the results, such as animosity toward the tax system, fairness, moral obligations to pay taxes, and the like, and also allows for a precise examination of the effect of changes in the included variables.

22. It is common to include a variable denoting "Wealth" (or accumulated earnings) in the econometric analysis. The justification is that individuals exhibiting decreasing absolute risk aversion preferences will comply less as wealth increases. Given that individuals comply less when their income is not subject to matching, wealth and the fraction of income not subject to matching (a treatment variable) are highly correlated. Thus, we do not include "Wealth."

\section{References}

Allingham, Michael G., and Agnar Sandmo. 1972. Income Tax Evasion: A Theoretical Analysis. Journal of Public Economics 1 (4): 323-38.

Alm, James, Roy Bahl, and Matthew N. Murray. 1993. Audit Selection and Income Tax Underreporting in the Tax Compliance Game. Journal of Development Economics 42 (1): 1-33.

Alm, James, Betty R. Jackson, and Michael McKee. 1992. Estimating the Determinants of Taxpayer Compliance with Experimental Data. National Tax Journal 65 (1): 107-14.

- - - 1993. Fiscal Exchange, Collective Decision Institutions, and Tax Compliance. Journal of Economic Behavior and Organization, 22 (3): 285-303.

Alm, James, and Michael McKee. 2006. Audit Certainty and Taxpayer Compliance. National Tax Journal 59 (4): 801-16.

Andreoni, James, Brian Erard, and Jonathan Feinstein. 1998. Tax Compliance. Journal of Economic Literature 36 (2): 818-60.

Bruce, Donald. 2000. Effects of the United States Tax System on Transitions into Self-Employment. Labour Economics 7 (4): 545-74.

Clotfelter, Charles T. 1983. Tax Evasion and Tax Rates: An Analysis Of Individual Returns. The Review of Economics and Statistics 65 (3): 363-73.

Cummings, Ronald, Jorge Martinez-Vazquez, and Michael McKee. 2006. Experimental Evidence on Mixing Modes of Income Tax Evasion. Public Finance Review 34 (6): 687-711.

Erard, Brian, and Chih-Chin Ho. 2001. Searching for Ghosts: Who are the Nonfilers and How Much Tax Do They Owe? Journal of Public Economics 81 (1): 25-50. 
Feinstein, Jonathan S. 1991. An Econometric Analysis of Income Tax Evasion and Its Detection. RAND Journal of Economics 22 (1): 14-35.

Gerxhani, Klarita, and Arthur Schram. 2006. Tax Evasion and the Source of Income. Journal of Economic Psychology 27 (3): 402-22.

Joulfaian, David, and Mark Rider. 1998. Differential Taxation and Tax Evasion by Small Business. National Tax Journal 51 (4): 675-87.

Kagan, Robert A. 1989. On the Visibility of Income Tax Law Violations. In Taxpayer Compliance, Vol. 2: Social Science Perspectives, ed. Jeffrey Roth and John T. Scholz (Philadelphia, PA: University of Pennsylvania Press), 76-125.

Madeo, Silvia A., Albert Schepanski, and Wilfred C. Uecker. 1987. Modeling Judgments of Taxpayer Compliance. The Accounting Review 62 (2): 323-42.

Martinez-Vazquez, Jorge, and Mark Rider. 2005. Multiple Modes of Tax Evasion: Theory and Evidence. National Tax Journal 58 (1): 51-76.

Plott, Charles R. 1987. Dimensions of Parallelism: Some Policy Applications of Experimental Methods. In Laboratory Experimentation in Economics: Six Points of View, ed. Alvin E. Roth, 193-219. New York: Cambridge University Press.

Robson, Martin T., and Colin Wren. 1999. Marginal and Average Tax Rates and the Incentive for selfemployment. Southern Economic Journal 64 (4): 757-73.

Scheutze, Herbert, and Donald Bruce. 2004. Tax Policy and Entrepreneurship. Swedish Economic Policy Review 11 (2): 235-65.

Schram, Arthur. 2005. Artificiality: The Tension Between Internal and External Validity in Economic Experiments. Journal of Economic Methodology 12 (2): 225-37.

Smith, Vernon. 1982. Microeconomic Systems as an Experimental Science. The American Economic Review 72 (5): 923-55.

U.S. General Accounting Office. 1990. Tax Administration: Profiles of Major Elements of the Tax Gap. Document GGD-90-53BR. Washington, DC: GAO.

Witte, Ann D., and Diane F. Woodbury. 1985. The Effect of Tax Laws and Tax Administration on Tax Compliance: The Case of the U.S. Individual Income Tax. National Tax Journal 38 (1): 1-13.

Wooldridge, J. M. 2002. Econometric Analysis of Cross Section and Panel Data. Cambridge, MA: The MIT Press.

Yitzhaki, Shlomo. 1974. A Note on Income Tax Evasion: A Theoretical Analysis. Journal of Public Economics 3 (2): 201-02. 